\title{
Organic matter composition and the protist and nematode communities around anecic earthworm burrows
}

\author{
Walter S. Andriuzzi ${ }^{1,2,10}$ (1) $\cdot$ Phuong-Thi Ngo $^{3} \cdot$ Stefan Geisen $^{4,5} \cdot$ Aidan M. Keith $^{6}$. \\ Kenneth Dumack $^{4} \cdot$ Thomas Bolger $^{7} \cdot$ Michael Bonkowski $^{4} \cdot$ Lijbert Brussaard $^{2}$ • \\ Jack H. Faber ${ }^{8}$ • Abad Chabbi ${ }^{3,9}$. Cornelia Rumpel ${ }^{3}$ - Olaf Schmidt ${ }^{1}$
}

Received: 26 January 2015 /Revised: 24 August 2015 / Accepted: 28 August 2015 / Published online: 12 September 2015

(C) The Author(s) 2015. This article is published with open access at Springerlink.com

\begin{abstract}
By living in permanent burrows and incorporating organic detritus from the soil surface, anecic earthworms contribute to soil heterogeneity, but their impact is still understudied in natural field conditions. We investigated the effects of the anecic earthworm Lumbricus centralis on fresh carbon (C) incorporation, soil organic matter composition, protists, and nematodes of a Cambisol under grassland. We used plant material labelled with stable isotope tracers to detect fresh $\mathrm{C}$ input around earthworm-occupied burrows or around burrows from which the earthworm had been removed. After 50 days, we sampled soil $(0-10 \mathrm{~cm}$ depth) in concentric layers around the burrows, distinguishing between drilosphere $(0-8 \mathrm{~mm})$ and bulk soil $(50-75 \mathrm{~mm})$. L. centralis effectively incorporated fresh $\mathrm{C}$ into the drilosphere, and this shifted soil organic matter amount and chemistry: total soil sugar content was
\end{abstract}

Electronic supplementary material The online version of this article (doi:10.1007/s00374-015-1056-6) contains supplementary material, which is available to authorized users.

Walter S. Andriuzzi

ws.andriuzzi@gmail.com

1 UCD School of Agriculture and Food Science, University College Dublin, Belfield, Dublin 4, Dublin, Ireland

2 Department of Soil Quality, Wageningen University, P.O. Box 47, 6700 AA Wageningen, The Netherlands

3 CNRS, Ecosys (UMR, INRA AgroParisTech), Campus AgroParisTech, Bâtiment EGER, 78850 Thiverval-Grignon, France

4 Department of Terrestrial Ecology, Institute for Zoology, University of Cologne, 50674 Cologne, Germany

5 Department of Terrestrial Ecology, Netherlands Institute for Ecology (NIOO-KNAW), Postbus 50, 6700 AB Wageningen,

The Netherlands increased compared to unoccupied drilosphere and bulk soil, and the contribution of plant-derived sugars to soil organic matter was enhanced. Earthworms also shifted the spatial distribution of soil $\mathrm{C}$ towards the drilosphere. The total abundance of protists and nematodes was only slightly higher in earthworm-occupied drilosphere, but strong positive effects were found for some protist clades (e.g. Stenamoeba spp.). Additional data for the co-occurring anecic earthworm species Aporrectodea longa showed that it incorporated fresh C less than $L$. centralis, suggesting that the two species may have different effects on soil $\mathrm{C}$ distribution and organic matter quality.

Keywords Decomposition - Lumbricidae - Nematodes · Protists $\cdot$ Soil organic matter $\cdot$ Stable isotope tracers
6 Centre for Ecology and Hydrology, Library Avenue, Bailrigg, Lancaster LA1 4AP, UK

7 UCD School of Biology and Environmental Science, University College Dublin, Belfield, Dublin 4, Dublin, Ireland

8 Alterra Wageningen University and Research Centre, PO Box 47, 6700 AA Wageningen, The Netherlands

$9 \quad$ INRA-Unité de Recherches Pluridisciplinaires sur la Prairie et les Plantes Fourragères, Lusignan, France

10 Department of Biology and School of Global Environmental Sustainability, Colorado State University, Fort Collins, CO 80523-1036, USA 


\section{Introduction}

Anecic earthworms forage at the soil surface for organic detritus which they bring inside their vertical burrows and translocate large amounts of organic matter belowground (Hale et al. 2005; Nuutinen 2011). Together with the earthworms' excreta, the soil near the burrows forms the 'drilosphere', a microhabitat that acts as a hotspot of many edaphic processes, such as $\mathrm{C}$ and $\mathrm{N}$ incorporation (Andriuzzi et al. 2013; Fahey et al. 2013), mineralization (Don et al. 2008), and nitrification and denitrification (Parkin and Berry 1999). These functions are associated with, and partly driven by, enhanced biological activity. For instance, the soil around burrows of Lumbricus terrestris supports bacterial communities that can respond rapidly to the earthworm-mediated input of fresh organic detritus (Tiunov and Scheu 1999).

Considering their widespread presence, anecic earthworms can be a major driver of soil heterogeneity. However, few studies have analysed the quantity and composition of the soil organic matter (SOM) in the drilosphere (Szlavecz 1985; Don et al. 2008), and none tested the effects of anecic earthworms experimentally. This is the first knowledge gap that we address here, as both the quantity and the quality of organic matter are important to biochemical cycling in soil.

Some studies have shown that protists and nematodes can reach higher abundance in $L$. terrestris middens and burrows compared to bulk soil, and significant shifts in community composition have been reported for nematodes (Görres et al. 1997; Maraun et al. 1999; Tiunov et al. 2001a; Tao et al. 2009). However, most studies have been performed on repacked soil in laboratory conditions, and very few have investigated nematodes and protists around natural burrows in the field. In a rare example of the latter, Stromberger et al. (2012) analysed phospholipid fatty acids inside and outside the drilosphere of $L$. terrestris, showing this microhabitat hosts' distinct microfaunal communities. However, the markers used in that study were not specific enough to discriminate between eukaryotic groups, for instance, protists and nematodes, and thus no conclusion on their relative abundance could be made (Stromberger et al. 2012). Hence, the second knowledge gap we address is how the small-scale heterogeneity in SOM quality and quantity driven by earthworm activity may influence protist and nematode community composition.

We performed a field experiment in a temperate grassland soil to test the effects of anecic earthworms on drilosphere soil biochemistry and on abundance and community composition of protists and nematodes associated with naturally formed burrows. Traditionally, the drilosphere around burrows has been delimited as a 2-mm-thick layer, but this has recently been shown to be an underestimation for the anecic L. terrestris (Andriuzzi et al. 2013). We focused on L. centralis (Bouché), which is morphologically and ecologically similar to the widespread $L$. terrestris. In addition, we were able to sample soil around the burrows of a cooccurring species, Aporrectodea longa (Ude), also traditionally classified as anecic. We provided plant material enriched in $\mathrm{C}$ stable isotopes $\left({ }^{13} \mathrm{C}\right)$ around the surface openings of natural burrows occupied by one of the two target species or from which the earthworm had been removed. We measured the incorporation of fresh surface-derived $\mathrm{C}$ and analysed the composition of sugars in the SOM within a radius of $8 \mathrm{~mm}$ around burrow walls (drilosphere) and $5 \mathrm{~cm}$ away (bulk soil); we focused on non-cellulosic sugars as they provide indications on the relative contribution of fresh and decomposed organic matter (see methods for details). Finally, we assessed the effects of earthworm presence (L. centralis) on abundance of protists, in total, and divided into morphologically determined clades, and on nematodes, in total, and divided into families and feeding groups. We tested the hypotheses that the drilosphere is a hotspot of incorporation of fresh organic matter from the soil surface; that it supports higher abundance of protists and nematodes than bulk soil; and that earthworm activity is necessary to maintain this status as a soil biochemical and biological hotspot.

\section{Materials and methods}

\section{Experimental design and data collection}

The field experiment was performed between April and May 2013 in Lusignan, France $\left(46^{\circ} 25^{\prime} 12.91^{\prime \prime} \mathrm{N}, 0^{\circ} 07^{\prime}\right.$ $29.35^{\prime \prime} \mathrm{E}$ ). The site is part of the SOERE ACBB (http:// www.soere-acbb.com/), which investigates the impact of agricultural management on soil biogeochemical cycles and biodiversity. Soil type is Cambisol with a silty-loamy texture (Chabbi et al. 2009), no $\mathrm{CaCO}_{3}, \mathrm{pH} 6.4$, organic C $14.0 \mathrm{~g} \mathrm{~kg}^{-1}$

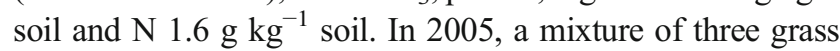
species was sown (Lolium perenne, Festuca arundinacea and Dactylis glomerata), with the addition of $120 \mathrm{~kg} \mathrm{~N} \mathrm{ha}^{-1}$ year

${ }^{1}$. Grass was mown at $5-\mathrm{cm}$ height and removed 2 days before the experimental set-up.

Plant material enriched in ${ }^{13} \mathrm{C}$ was produced in a greenhouse at the University College Dublin (Ireland). Two-weekold maize seedlings (Zea mays) were labelled using the urea leaf-feeding method of Schmidt and Scrimgeour (2001), by daily spraying with a ${ }^{13} \mathrm{C}$-enriched urea solution (97 atom\% ${ }^{13} \mathrm{C}$ ). To further boost ${ }^{13} \mathrm{C}$ labelling, the seedlings were enclosed for 2 (non-consecutive) days in commercially available transparent polyethylene bags that can be hermetically sealed; by inserting a thin tube under a sealable cap, acid $(35 \% \mathrm{HCl})$ was injected into a vial containing $99 \%{ }^{13} \mathrm{C}$ sodium bicarbonate just before sealing, releasing ${ }^{13} \mathrm{C}$-enriched $\mathrm{CO}_{2}$. Labelling lasted 10 days (8 days urea, 2 days sodium bicarbonate). The maize shoots were harvested and cut into 5- 
$\mathrm{mm}$ fragments, which were thoroughly mixed and transported fresh to the field site after 2 days. We recognize that this material (from young, green plants, high in $\mathrm{N}$ ) does not represent actual litter or residue from senescent plants, but comparable material is available to soil animals through agronomic practices such as green manure, mulching and cover cropping.

The openings of anecic earthworm burrows $(n=28)$, made by either $L$. centralis or $A$. longa, were located by visual inspection of the soil surface in a $400 \mathrm{~m}^{2}$ area, and an experimental design based on Andriuzzi et al. (2013) was applied. A minimum distance of $1 \mathrm{~m}$ between burrows was deemed sufficient for independence of replicates. To establish an exclusion treatment to test earthworm presence effects, the resident anecic earthworms were removed from nine burrows, which later received labelled material, using $50 \mathrm{ml}$ of a $0.2 \%$ $v / v$ allyl-isothiocyanate solution (AITC) as in Stromberger et al. (2012). The solution was injected with a syringe and did not touch the burrows' walls in the top $10 \mathrm{~cm}$ of soil. Nevertheless, to account for the potential confounding effects of AITC and earthworm removal, anecic earthworms were removed by the same procedure from another nine burrows and then re-introduced after rinsing with water. Additionally, occupied burrows $(n=4)$ were chosen as isotopic controls; that is, they were not given the labelled maize in order to measure the natural isotope abundance.

All burrows, including the isotopic controls, were rinsed with $0.5 \mathrm{~L}$ of water to wash down AITC and avoid water addition biases. The burrows from which the anecic earthworms were successfully removed are hereafter referred to as 'unoccupied burrows', but smaller invertebrates were active around them, e.g. smaller earthworms and slugs were observed during sampling. In an 8 -cm radius around each burrow opening, $10 \pm 0.2 \mathrm{~g}$ of the labelled maize were placed on the soil surface and fixed with a metal mesh cage $(0.5 \mathrm{~cm}$ mesh size) to prevent displacement by wind and rain.

\section{Sample collection}

After 50 days, mesh cages were removed. No maize material was detected above the earthworm-occupied burrows, while fragments were still found above unoccupied burrows. Dilute AITC was injected into the burrows to expel resident earthworms as described above, and intact soil blocks $(15 \times 15 \mathrm{~cm}$, $10 \mathrm{~cm}$ deep) containing individual burrows were excavated with a knife. Earthworm presence/removal or burrow structure could not be ascertained in some samples, reducing the sample size (see "Stable isotope ratio and non-cellulosic sugar analyses" and "Biotic analyses").

Shortly after collection, the soil blocks were transported to a laboratory. Using a mini spatula, four concentric layers $(0-2$, $>2$ to $4,>4$ to 8 and $50-75 \mathrm{~mm}$ ) were taken around each burrow. Samples were sub-divided for chemical (SOM and stable isotopes) and biotic analyses (abundance of protists and nematodes); due to the different requirements of soil amount and difficulty in separating some layers in some samples, not all analyses could be performed. After weighing, earthworms were fixed in pure ethanol, and caudal segments were cut, dissected and freeze-dried (unlabelled controls $n=2$ L. centralis, $n=2$ A. longa; labelled $n=5 L$. centralis, $n=2$ A. longa).

\section{Stable isotope ratio and non-cellulosic sugar analyses}

Soil samples for chemical analyses were oven-dried at $50{ }^{\circ} \mathrm{C}$ for $24 \mathrm{~h}$. A sub-set was analysed for stable isotope ratios (isotopic controls $n=3$ replicates $\times 4$ concentric layers; isotopically labelled $n=7 \times 4$ unoccupied, $n=4 \times 4 L$. centralis, $n=2 \times$ $4 \mathrm{~A}$. longa). Oven-dried soil and freeze-dried earthworm samples were powdered in a ball mill (Mixer Mill MM 200, Retsch, Haan, Germany), weighed into tin capsules and sent to Iso-Analytical Ltd. (Cheshire, UK) for the analysis of stable isotope $\mathrm{C}$ and $\mathrm{N}$ ratios, and total $\mathrm{C}$ and $\mathrm{N}$ concentrations with an Elemental Analyser-Isotope Ratio Mass Spectrometer (Europa Scientific 20-20). Ethanol preservation is assumed to have only minor effects on intact tissue ${ }^{13} \mathrm{C}$ signatures (Sarakinos et al. 2002). Isotopic values are expressed in the $\delta$-notation in parts per thousand (\%). The maize shoots were highly and consistently enriched in ${ }^{13} \mathrm{C}\left(\delta^{13} \mathrm{C}=3432.9 \pm 2.8\right.$ $\%, n=3$ ) compared to plant material in the $\mathrm{C}_{3}$-dominated grassland site $\left(-31 \%<<\delta^{13} \mathrm{C}<-29 \%\right.$, Sanaullah et al. 2010).

The three layers considered as drilosphere following Andriuzzi et al. (2013) (hereafter designated as 0-2, 2-4 and 4-8 $\mathrm{mm}$ ) were pooled to obtain sufficient material for SOM analysis (labelled only $n=4$ unoccupied, $n=4 L$. centralis, $n=4$ A. longa). Neutral non-cellulosic sugars were analysed using gas chromatography after hydrolysis (Rumpel and Dignac 2006). Briefly, $1 \mathrm{~g}$ of soil was hydrolysed using $10 \mathrm{ml}$ of $4 \mathrm{M}$ TFA at $110^{\circ} \mathrm{C}$ for $4 \mathrm{~h}$, and sugar monomers were transformed into acid alditols. The monosaccharides were recovered and analysed with a HP 6890 gas chromatograph equipped with a flame ionization detector and a silica capillary column (BPX 70, 60-m long, 0.32-mm internal diameter, 0.25 -mm film thickness). The following temperature program was used: from $200^{\circ} \mathrm{C}$ to $250^{\circ} \mathrm{C}$ at $3{ }^{\circ} \mathrm{C} \mathrm{min}^{-1}$, isothermal for $15 \mathrm{~min}$. The total sugars were calculated as the sum of all individual monosaccharides. The ratio of (galactose + mannose) to (arabinose+xylose), or GM/AX, was used as an indicator of sugar origin: the lower the ratio, the larger the contribution of fresh plant-derived material.

\section{Biotic analyses}

Protists and nematodes in drilosphere $(0-8 \mathrm{~mm})$ and bulk soil were extracted from $L$. centralis burrows $(n=4$ replicates $\times 2$ microhabitats) and unoccupied burrows $(n=5 \times 2)$. The soil samples for extraction of protists were kept at $4{ }^{\circ} \mathrm{C}$ and sent 
to the University of Cologne (Germany) in a cooled Styrofoam box within $48 \mathrm{~h}$ of collection. Nematodes were extracted from another set of soil samples ( $1 \mathrm{~g}$ each) shortly after collection, by mixing the soil with water $(10 \mathrm{ml})$, heating at $60{ }^{\circ} \mathrm{C}$ for $2 \mathrm{~min}$ and then adding formaldehyde (final concentration $4 \%$ ), before shipping to SRUC (Edinburgh, UK).

The protists were enumerated using a modified version of the liquid aliquot method (LAM) according to Butler and Rogerson (1995), with slight modifications as described in Geisen et al. (2014a), and identified with an inverted microscope (Nikon Eclipse TS100) at $\times 100$ and $\times 200$ magnifications. Protists were determined to morpho-group level according to Lee et al. (2000), Smirnov and Brown (2004), Smirnov et al. (2011) and Jeuck and Arndt (2013). Naked amoebae were identified up to genus level according to the most recent phylogeny, and individual genera were subsequently grouped into different higher taxonomic levels (Smirnov et al. 2011). The total numbers of flagellates and amoebae per gramme dry weight soil were calculated from the cumulative abundances in microtiter plates and the respective dilution of soil.

The nematodes were counted at $\times 40$ magnification to estimate abundance, identified to family level and allocated to feeding groups: bacterial feeding, fungal feeding, plant parasites, plant-associated (i.e. feeding on root hairs and mycorrhizal hyphae), omnivores and predators (Yeates et al. 1993). Due to low numbers, omnivores and predators were merged, and fungal feeding and plant-associated nematodes were combined into hyphal feeding (the latter also reflecting uncertain trophic classification of plant-associated nematodes found, e.g. Tylenchus-see Yeates et al. 1993).

\section{Statistical analyses}

To verify the efficacy of the stable isotope tracers, a linear mixed-effect model on soil $\delta^{13} \mathrm{C}$ around earthwormoccupied burrows was fitted, using burrow identity as random effect and labelled plant material presence as fixed effect, and subjected to a marginal Wald $F$-test (suitable to unbalanced designs). Means and standard errors of earthworm body $\delta^{13} \mathrm{C}$ were calculated separately for labelled and unlabelled specimens (the large difference in variance prevented a direct statistical comparison).

Subsequent analyses were restricted to burrows provided with the labelled plant material. The interactive effects of L. centralis (present vs removed) and microhabitat (drilosphere layers vs bulk soil) on soil $\delta^{13} \mathrm{C}, \mathrm{C}$ and $\mathrm{N}$ contents, and $\mathrm{C} / \mathrm{N}$ ratios were analysed in linear mixed-effect models with burrow as random effect. AITC use was included as factor to test for undesired biases, but none were detected. To account for potential body size effects, the analyses were repeated with earthworm weight as covariate, and Spearman's correlation coefficient between earthworm weight and body $\delta^{13} \mathrm{C}$ was calculated. The effects of $L$. centralis presence on the GM/AX ratio and total sugar content of SOM in the drilosphere $(0-8 \mathrm{~mm})$ were analysed with general linear models. We report data for $A$. longa but do not include them in the main statistical analyses because of the low number of suitable samples for this species.

The effects of $L$. centralis' presence and microhabitat (drilosphere vs bulk soil) on abundance (individuals $\mathrm{g}^{-1}$ soil) of nematodes, in total and for each feeding group, and of protists, in total and for taxonomic groups, were tested in linear mixed-effect models with burrow as random effect. The potential differences in the taxonomic composition of protists and nematodes between soil around occupied and unoccupied burrows were visualized with non-metric multidimensional scaling ordination (NMDS), based on a BrayCurtis dissimilarity matrix generated on the abundance of nematode families or protist groups, and tested with nonparametric multivariate analysis of variance (nPMANOVA), which compared the observed data with 1000 random permutations.

Results are reported as mean \pm standard error (SE) with associated $p$-values estimated from the models; post hoc multiple comparisons were carried out with Tukey HSD when appropriate ( $\geq 10$ pairwise comparisons). Homogeneity and normality assumptions were checked by visual inspection of the residuals. The variance explained by the mixed-effect models was estimated as conditional $R^{2}$ (which includes the random effect, i.e. accounts for variability between burrows) and marginal $R^{2}$ (only the fixed effects) following Nakagawa and Schielzeth (2012). Analyses were done in R 2.15.0 (R Development Core Team 2013), using libraries "nlme" (Pinheiro et al. 2013) and "vegan" (Oksanen et al. 2012).

\section{Results}

\section{Incorporation of fresh $\mathrm{C}$ into soil and earthworm tissue}

Soil that had received the labelled plant material was significantly enriched in ${ }^{13} \mathrm{C}$ compared to the isotopic controls $(0$ 10-cm depth, all concentric layers pooled as follows: $\delta^{13} \mathrm{C}=$ $-25.86 \pm 0.56 \%$ vs $-27.88 \pm 0.07 \%, p<0.01$ ). Around the burrows under labelled material, average soil $\delta^{13} \mathrm{C}$ was higher in $L$. centralis drilosphere soil $(0-8 \mathrm{~mm})$ than unoccupied drilosphere soil $(-23.43 \pm 1.02 \%$ vs $-27.25 \pm 1.37 \%$, $p=$ 0.03 ), pointing to a larger incorporation of plant-derived $C$ (Fig. 1). The mixed-effect model explained almost $60 \%$ of the total variance (conditional $R^{2}=0.57$ ), but less than half as much once the influence of the burrow random effect was removed (marginal $R^{2}=0.22$ ), indicating that the variability between burrows was important. The few available $A$. longa burrows $(n=2)$ had lower soil $\delta^{13} \mathrm{C}$ values than $L$. centralis burrows ( $-27.08 \pm 0.31 \%$ in the drilosphere). 


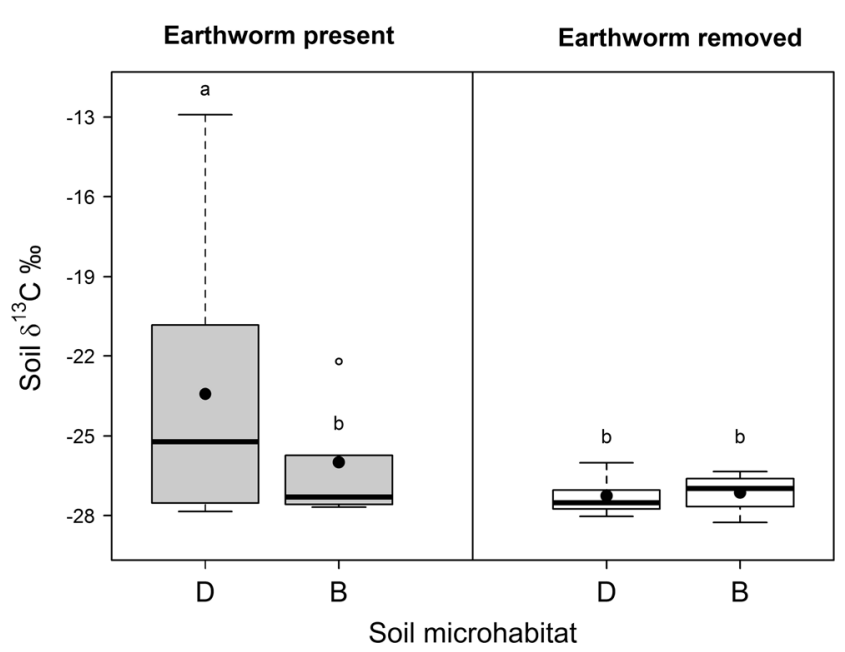

Fig. $1 \mathrm{C}$ stable isotope ratios in soil (0-10-cm depth) around earthworm burrows occupied by $L$. centralis $(n=4)$ and burrows from which the earthworm had been expelled 50 days before sampling $(n=7)$, in the drilosphere $(D, 0-8 \mathrm{~mm}$ around burrow walls) and in bulk soil $(B, 50$ $75 \mathrm{~mm}$ around burrow walls). Maize fragments labelled with ${ }^{13} \mathrm{C}$ were placed near the burrow entrances at the start of the experiment. The thick lines inside the boxes are the medians, the black dots are the means, and the error bars outside the boxes delimit the interquartile range. Different letters mark significant differences $(p \leq 0.05)$

As expected, L. centralis specimens from the burrows under labelled maize had on average higher $\delta^{13} \mathrm{C}(1.67 \pm 11.85$ $\%$ ) than isotopic control specimens $(-21.00 \pm 0.13 \%$ ), but there was a very high variability. This indicates that some earthworms had fed on the labelled maize more than others; this did not depend on their body size (Spearman's $r=0.3, p=$ $0.69)$. Tissue $\delta^{13} \mathrm{C}$ of the $A$. longa specimens $(n=2)$ from labelled burrows was even more variable, ranging from -20.95 to $57.63 \%$.

\section{Soil $\mathrm{C}$ and SOM chemistry}

There was no overall difference in total $\mathrm{C}$ content between bulk soil and unoccupied L. centralis drilosphere (all layers $2.55 \pm 0.14 \%$ and $2.36 \pm 0.11 \%$ respectively, $p>0.10$ ) However, earthworm presence shifted the spatial distribution of $\mathrm{C}$ around burrows (Fig. 2): when a worm was resident, the total soil $\mathrm{C}$ was significantly higher in the drilosphere than in surrounding soil ( $p \leq 0.05$, Tukey HSD), whereas there was no difference around unoccupied burrows $(p>0.10)$. Again, the variability between burrows was high and had a substantial influence on the observed patterns (conditional $R^{2}=0.64$, marginal $R^{2}=0.16$ ). The earthworm effects on soil $\mathrm{C}$ were not driven by differences in individual body size, because adding individual weight as a covariate did not change the outcome (the covariate was non-significant, and $R^{2}$ increased only by $2 \%$ ). Like total $\mathrm{C}$ content, soil $\mathrm{C} / \mathrm{N}$ ratio was significantly $(p<0.01)$ higher in drilosphere than bulk soil when L. centralis was present $(11.18 \pm 0.19$ vs $10.04 \pm 0.11$, $p<0.01)$, whereas no such difference was found around

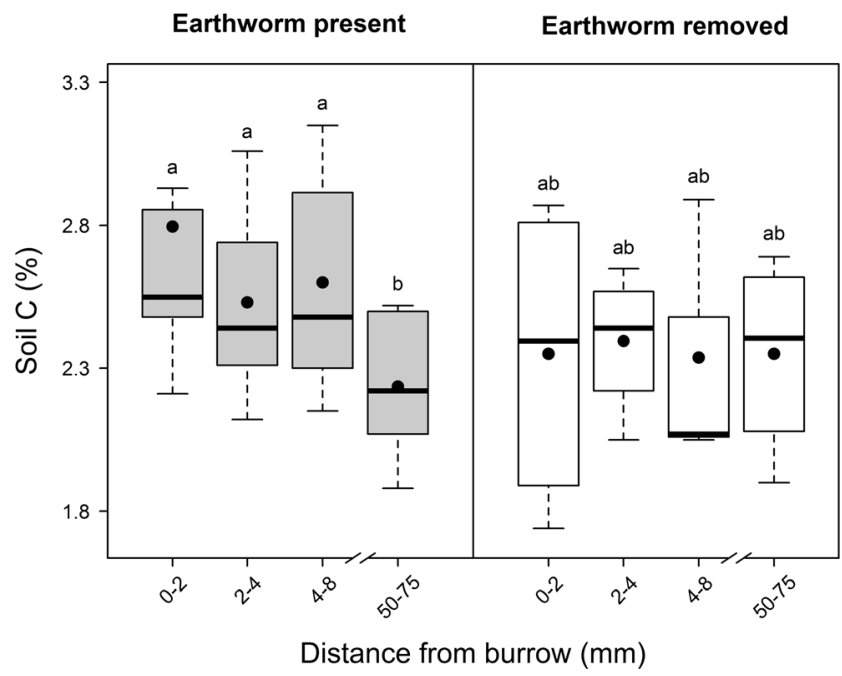

Fig. 2 Total $\mathrm{C}$ content in soil (0-10 $\mathrm{cm}$ depth) around burrows with a resident $L$. centralis $(n=4)$ and burrows from which the earthworm had been removed $(n=7)$. The thick lines and the dots inside the boxes are medians and means, respectively, and the error bars delimit the interquartile range. Different letters mark significant differences $(p \leq 0.05)$

unoccupied burrows $(10.56 \pm 0.18$ vs $10.62 \pm 0.03)$. Soil N content itself was neither affected by earthworm presence nor did it differ between drilosphere layers and bulk soil (both in the range $0.17-0.30 \%$ ).

The total sugar content in SOM (Fig. 3) was clearly higher $(p<0.01)$ around L. centralis burrows $\left(15.1 \pm 1.2 \mathrm{mg} \mathrm{g}^{-1}\right.$ soil $)$ than around unoccupied burrows $\left(9.2 \pm 1.6 \mathrm{mg} \mathrm{g}^{-1}\right.$ soil). The presence of a resident earthworm resulted in a higher relative contribution of plant-derived sugars to the SOM sugar pool, as revealed by the lower $\mathrm{GM} / \mathrm{AX}$ ratio $(0.56 \pm 0.04 \mathrm{~L}$. centralis, $0.82 \pm 0.06$ unoccupied, $p<0.01$, Fig. 3 ). The burrows with A. longa had total sugar content $(10.3 \pm 1.6 \mathrm{mg}$ per $\mathrm{g}$ of soil) more similar to that of unoccupied burrows than burrows of L. centralis, and the same was observed for the GM/AX ratio $(0.75 \pm 0.06)$.

\section{Effects of earthworm activity on protists and nematodes}

The total abundance of protists was not significantly influenced by the presence of $L$. centralis or the soil microhabitat (drilosphere vs bulk soil), although the highest numbers were recorded in the earthworm-occupied drilosphere (Fig. 4). NMDS ordination and npMANOVA (Supplementary material) did not reveal any potential difference in overall taxonomic composition between soil microhabitats. However, there were interactive effects of earthworm presence and microhabitat on some abundant clades within higher taxonomic clades, viz. the supergroup Amoebozoa and the phylum Cercozoa (Fig. 4 and Supplementary material).

In particular, monotactic amoebae of the amoebozoan class Tubulinea were more abundant in drilosphere than bulk soil around unoccupied burrows $(p=0.02)$, whereas they had 


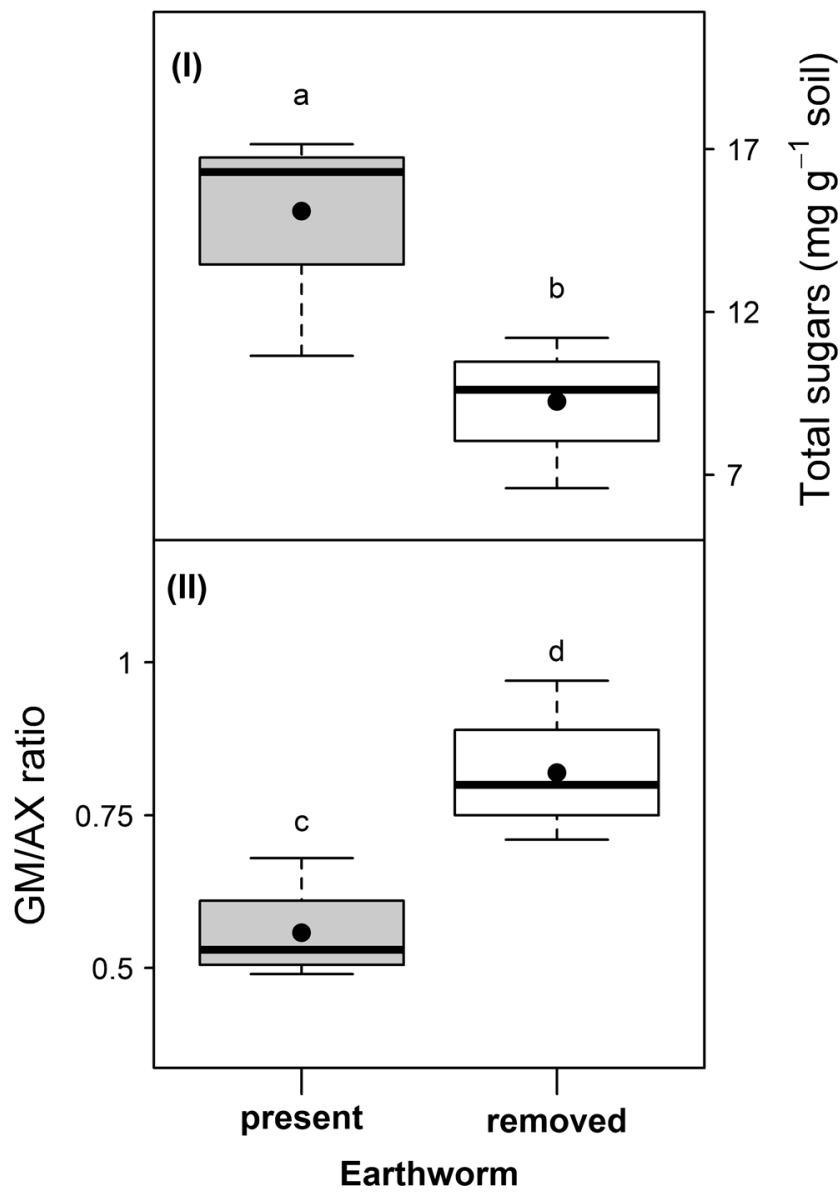

Fig. 3 Total sugar content $(I)$ and GM/AX ratio $(I I)$ in soil organic matter around burrows either occupied by L. centralis $(n=4)$ or with earthworm removed $(n=4) . \mathrm{GM} / \mathrm{AX}=($ galactose + mannose $) /($ arabinose + xylose $)$; the lower the ratio, the higher the relative contribution of plant-derived sugars vs microbial-derived sugars, indicating less decomposed organic matter. The thick lines and the dots inside the boxes are medians and means, respectively, and the error bars delimit the interquartile range. Different letters mark significant differences $(p \leq 0.05)$

similar abundances in the two microhabitats around occupied burrows ( $p>0.10$, Fig. 4). Within the amoebozoan class Discosea, amoebae of the genus Stenamoeba were more than twice as abundant in the drilosphere with $L$. centralis than in bulk soil ( $p=0.01$, Fig. 4 ), whereas an opposite pattern occurred around unoccupied burrows $(p=0.01)$. Amongst the amoeban classes, the larger-bodied Variosea were the least responsive (Fig. 4). Flagellates of the order Glissomonadida, from supergroup Cercozoa, were more abundant in the drilosphere than in bulk soil if the earthworm was present ( $p=0.04$ ), while Cercozoa on the whole were more abundant in drilosphere than in bulk soil, whether the earthworm was present or not ( $p<0.01$, Supplementary material).

The abundance of nematodes was not markedly affected by earthworm presence or soil microhabitat (drilosphere vs bulk soil $p>0.10$, mixed-effect models), but, similarly to protists, the highest numbers were found in the drilosphere around earthworm-occupied burrows (Fig. 4). There were no recognizable patterns in taxonomic composition (Supplementary material), whether the analysis included rare families or not (absent from $75 \%$ or more of the samples). Most nematodes were hyphal feeders, plant parasites or bacterial feeders (Supplementary material), with Tylenchidae $(52.0 \pm 4.9 \%)$ and Cephalobidae $(13.3 \pm 1.5 \%)$ as the most represented families.

\section{Discussion}

\section{Anecic earthworms maintain hotspots of fresh incorporated $\mathbf{C}$}

We confirmed that the drilosphere (in 0-10-cm depth) of the anecic earthworm $L$. centralis is much thicker than traditionally presumed (at least $8 \mathrm{~mm}$ as compared to $2 \mathrm{~mm}$ ), as was shown previously for $L$. terrestris in intact soil in the field (Andriuzzi et al. 2013). The added plant material was highly enriched in ${ }^{13} \mathrm{C}$ and indicated higher incorporation of surface $\mathrm{C}$ in the drilosphere than in bulk soil. Such $\mathrm{C}$ translocation might have been due to mobilization of soluble litter compounds (Gaillard et al. 2003), excretion of earthworm casts along the burrow walls, and possibly the activity of other invertebrates in and around the burrow, for instance microarthropods (Chamberlain et al. 2006). Whatever the mechanisms involved, the presence of active L. centralis played a key role, as demonstrated by the lower soil ${ }^{13} \mathrm{C}$ enrichment around burrows from which the resident earthworm had been removed a priori (Fig. 1). In this study we focused on topsoil, which is where most soil biological activity occurs, but the activity of anecic earthworms also affects deeper layers (Zaller et al. 2013).

As a result of earthworm-driven incorporation of fresh organic material, both the quantity and the quality of SOM were modified: soil in the drilosphere controlled by L. centralis had higher total sugar content and lower GM/AX ratio than in the drilosphere surrounding vacant burrows (Fig. 3). A larger proportion of the plant-derived sugars xylose and arabinose in the SOM sugar pool (= lower GM/AX) is diagnostic of a higher contribution of recently incorporated plant material, whereas a larger share of microbial sugars such as galactose and mannose $(=$ higher GM/AX) is linked to older and more stabilized organic matter (Spielvogel et al. 2008). All our samples had relatively low GM/AX ratios $(<1)$ compared to the bulk soil analysed in other studies (Spielvogel et al. 2008; Rumpel et al. 2010), indicating a high relative abundance of fresh plantderived sugars. This is not surprising, as burrows made by anecic earthworms are preferential pathways of detritus incorporation into soil, and the unoccupied burrows we sampled had been earthworm-free for only 50 days.

Despite the latter fact, earthworm presence led to a concentration of $\mathrm{C}$ in the drilosphere compared to the corresponding 
Protists

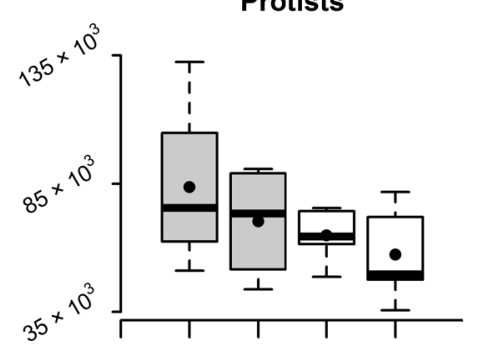

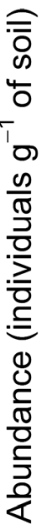

Tubulinea

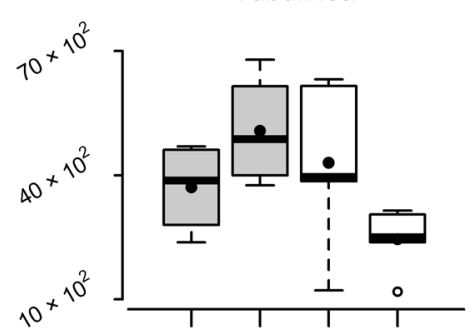

Discosea

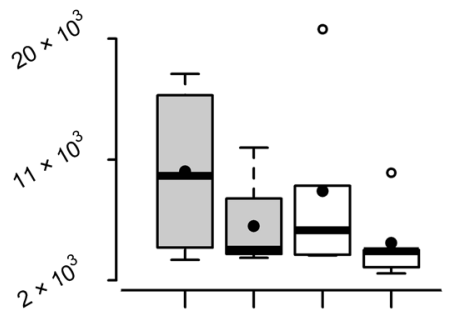

Heterolobosea

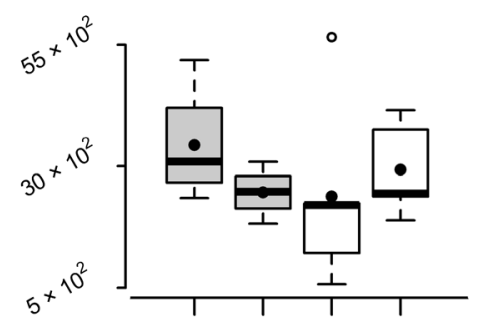

Hyphal-feeding nematodes

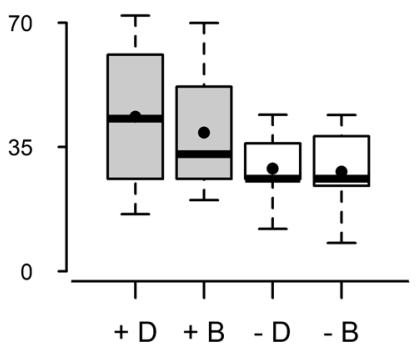

Stenamoeba sp

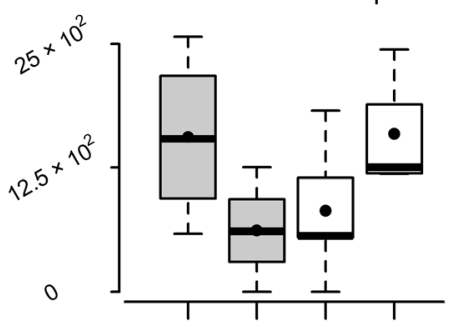

Plant-parasitic nematodes

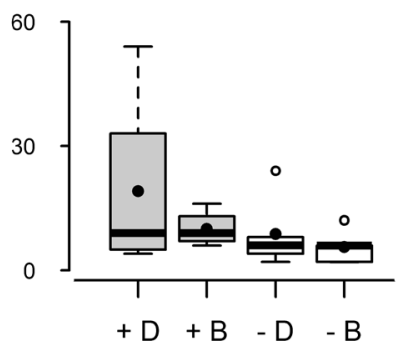

Fig. 4 Abundance of soil protists (top and middle rows) and nematodes (bottom row) in soil around burrows occupied by L. centralis $(+$, grey boxes) or from which the earthworm had been removed 50 days before sampling (-, white boxes), in drilosphere $(D ; 0-8 \mathrm{~mm}$ around burrow walls) and bulk soil $(B ; 50-75 \mathrm{~mm}$ around burrow walls). For protists, abundance is shown for the entire community, the four classes of

bulk soil, as recorded in other studies on anecic earthworm burrows (Don et al. 2008; Stromberger et al. 2012; but see Tiunov et al. 2001b). Notably, this did not occur around burrows from which the earthworms had been removed. While 50 days without a resident earthworm might have been enough for some $\mathrm{C}$ losses (e.g. through DOC leaching), a more likely explanation is that the earthworms mediated larger inputs of $\mathrm{C}$ from the labelled plant material to the soil, as indicated by both ${ }^{13} \mathrm{C}$ and SOM data (Figs. 1 and 3). Indeed, the drilosphere around isotopic control burrows, which were occupied by $L$. centralis but were not given the labelled plant material, had somewhat lower soil C concentrations (24.8 \pm $0.8 \mathrm{~g} \mathrm{~kg}^{-1}$ soil, $\left.n=4\right)$ than the labelled earthworm-occupied drilosphere (26.4 $\pm 1.3 \mathrm{~g} \mathrm{~kg}^{-1}$ soil, $\left.n=4\right)$. This earthwormmediated input of fresh organic matter into soil can affect the microbial community in the drilosphere, leading to faster turnover and higher enzymatic activity (Tiunov and Scheu 1999; Uksa et al. 2015) and to changes in community amoebae and the highly represented genus Stenamoeba (class Discosea). For nematodes, abundance is shown for the entire community and the two most abundant trophic groups. The thick lines in the boxes are the medians, the black dots are the means, and the error bars delimit the interquartile range

composition, e.g. possibly enhancing bacterial compared to fungal saprotrophs (Dempsey et al. 2013).

The earthworms occupying the burrows under labelled maize were only weakly enriched in ${ }^{13} \mathrm{C}$, and the individual variability in isotopic signature was high. Given the strong ${ }^{13} \mathrm{C}$ enrichment of the plant material, this high variability is surprising. Although a complete disappearance of the maize was observed above the burrows with anecic earthworms (suggesting their important role in litter degradation) and $L$. centralis effectively incorporated plant material belowground (Figs. 1 and 3), some individuals apparently assimilated little or negligible amounts of the labelled plant material. This could be partly explained by individual differences in consumption, meaning that some earthworms fed on the plant material for a shorter time than others. In fact, even though anecic earthworms may transport very fresh leaves inside their burrows (Griffith et al. 2013), they preferably feed on them only after they are more or less decayed and mixed with mineral soil 
(Doube et al. 1997). Another possibility is that due to the short labelling period, the stable isotope tracer in the maize fragments was mostly in highly labile fractions, which could have been lost during decomposition before residues were ingested by earthworms. The variation in earthworm body size was not influential, as individual weight was not a significant predictor in the statistical analyses.

\section{Protists and nematodes around anecic earthworm burrows}

Protists and nematodes attained higher average abundance in the presence of $L$. centralis, but burrow-to-burrow variability was high and resulted in a substantial overlap. We did not detect clear community-wide differences between drilosphere and bulk soil, although the highest abundance of both groups was measured in earthworm-occupied drilosphere (Fig. 4). Earthworms may provide protists and nematodes with advantageous conditions in the drilosphere through nutrient enrichment, stable soil moisture and higher microbial activity, and possibly enhanced pore space (Görres and Amador 2010). Moreover, earthworms feed on protists (e.g. naked amoebae) and nematodes (Dash et al. 1980; Bonkowski and Schaefer 1997), and so they might regulate their community composition and abundance also via direct trophic effects.

In a laboratory experiment with $L$. terrestris and two types of leaf litter, nematodes were consistently more abundant in the drilosphere $(0-4 \mathrm{~mm})$ than outside, while for protists the same occurred under litter from Tilia cordata but not Fagus sylvatica (Tiunov et al. 2001a). In our study, the trophic structure of the soil nematode community was little affected by earthworm presence and soil microhabitat, whereas there were clearer effects on the taxonomic composition of protists. For instance, Cercozoa and in particular Glissomonadida, a dominant group of bacterial-feeding soil flagellates (Howe et al. 2009), were more numerous in the drilosphere, whether L. centralis was present or not (Supplementary material). Also the abundance of Stenamoeba spp., a species-rich genus within the eukaryotic supergroup Amoebozoa (Geisen et al. 2014b), was higher in drilosphere than in corresponding bulk soil when $L$. centralis was present but was depressed in the drilosphere when the burrow was abandoned (Fig. 4). This finding corresponds with the increased numbers of amoebae of Vannella morphotypes (which previously included Stenamoeba) in L. terrestris middens reported by Anderson and Bohlen (1998). Desiccation sensitive protists such as Stenamoeba (Geisen et al. 2014a) might have especially benefitted from the moisture conditions in the active drilosphere, characterized by frequent mucus secretion by the earthworm. The enriched microfauna in Lumbricus burrows may contribute to fast nutrient cycling by grazing on microbes and thereby influencing microbial turnover, enzymatic activity and community composition, as well as through the release of nutrients otherwise locked in microbial cells (Bonkowski 2004). However, still far too little is known on how changes in the protist community composition may affect the rest of the soil food web.

\section{Do anecic earthworm species have similar effects on soil biogeochemistry?}

Our results obtained from real, natural earthworm burrows highlight the variability and the difficulties associated with field-based experiments compared to laboratory approaches (Kampichler et al. 2001). Issues with validating earthworm presence (or removal) in target burrows and with the collection of the required amount of soil for the various analytical methods impeded a rigorous statistical comparison of $A$. longa and $L$. centralis. Nevertheless, our data suggest that $A$. longa incorporated less surface organic matter into soil than L. centralis, so that its drilosphere was more comparable to bulk soil or soil around unoccupied burrows (e.g. in soil $\delta^{13} \mathrm{C}$ and GM/AX ratio). If confirmed, this would mean that the two anecic species had specific effects on soil biogeochemical and biological heterogeneity under the given field conditions due to different effect traits related to the incorporation of surface organic matter. Such difference would be consistent with traditional niche theory (Leibold 1995), according to which a strong functional overlap of two co-occurring species must lead to the competitive exclusion of one of them. In fact, although soil is a highly heterogeneous environment where competing species may co-occur at small scales (Amarasekare 2003)-the so-called enigma of soil animal diversity (Anderson 1975)-trait differences between cooccurring anecic earthworm species have been found. In particular, A. longa feeds more extensively on highly mineralized SOM than do Lumbricus spp., the latter showing a stronger preference for fresher detritus (Briones et al. 2005; Thakuria et al. 2010). Also, the burrowing behaviour of $A$. longa appears somewhat intermediate between that of endogeic earthworms, which dig transient channels below the soil surface, and true anecic earthworms (Bastardie et al. 2005). But it should be noted that $A$. longa and other anecic species are remarkably flexible in their diet (Schmidt 1999; Thakuria et al. 2010; Griffith et al. 2013), as they tune their behaviour according to environmental conditions (e.g. availability of surface residues).

\section{Conclusions}

The anecic earthworm L. centralis incorporates fresh organic $\mathrm{C}$ into soil around its burrows, altering both the quantity and the chemical quality of the soil $\mathrm{C}$ pool in this microhabitat. Soil around burrows that did not have a resident earthworm during the experiment (50 days) was biochemically more 
similar to soil beyond earthworm influence than to earthworm-occupied drilosphere soil, indicating that for biogeochemical effects to be persistent, the earthworm has to be present. While earthworm presence had small effects on the overall abundance of nematodes or protists in the drilosphere, it stimulated some phylogenetic clades of protists. Additional data on the co-occurring anecic earthworm $A$. longa hinted at the possibility that distinct species in the anecic functional group may differ in their effects due to niche differentiation, in particular, in terms of incorporation of surface detritus belowground.

Acknowledgments We thank the SOERE ACBB for providing access to the experimental site, Jean-François Bouhiron, Xavier Charrier and Alice Auffrais (INRA) for on- and off-site support, Guénola Pérès and her team (Université de Rennes 1) for providing data on the earthworm species of the field site, Jens Dyckmans (Goettingen University) for technical advice on the production of stable isotope-enriched $\mathrm{CO}_{2}$, Bryan Griffiths (SRUC) for help with nematode extraction, and two anonymous reviewers and the editor-in-chief for constructive comments. This research was funded by the European Commission through the EcoFINDERS project (FP7-264465) and by the Irish Research Council and French Embassy/Campus France through a Ulysses grant.

Open Access This article is distributed under the terms of the Creative Commons Attribution 4.0 International License (http:// creativecommons.org/licenses/by/4.0/), which permits unrestricted use, distribution, and reproduction in any medium, provided you give appropriate credit to the original author(s) and the source, provide a link to the Creative Commons license, and indicate if changes were made.

\section{References}

Amarasekare P (2003) Competitive coexistence in spatially structured environments: a synthesis. Ecol Lett 6:1109-1122

Anderson J (1975) The enigma of soil animal species diversity. In: Vaněk $\mathrm{J}$ (ed) Progress in soil zoology. Springer, Netherlands, pp 51-58

Anderson OR, Bohlen PJ (1998) Abundances and diversity of gymnamoebae associated with earthworm (Lumbricus terrestris) middens in a northeastern US forest. Soil Biol Biochem 30:12131216

Andriuzzi WS, Bolger T, Schmidt O (2013) The drilosphere concept: fine-scale incorporation of surface residue-derived $\mathrm{N}$ and $\mathrm{C}$ around natural Lumbricus terrestris burrows. Soil Biol Biochem 64:136138

Bastardie F, Capowiez Y, Renault P, Cluzeau D (2005) A radio-labelled study of earthworm behaviour in artificial soil cores in term of ecological types. Biol Fertil Soils 41:320-327

Bonkowski M (2004) Protozoa and plant growth: the microbial loop revisited. New Phytol 162:617-631

Bonkowski M, Schaefer M (1997) Interactions between earthworms and soil protozoa: a trophic component in the soil food web. Soil Biol Biochem 29:499-502

Briones MJ, Garnett M, Piearce TG (2005) Earthworm ecological groupings based on ${ }^{14} \mathrm{C}$ analysis. Soil Biol Biochem 37:2145-2149

Butler H, Rogerson A (1995) Temporal and spatial abundance of naked amoebae (Gymnamoebae) in marine benthic sediments of the Clyde Sea area, Scotland. J Eukaryot Microbiol 42:724-730
Chabbi A, Kögel-Knabner I, Rumpel C (2009) Stabilised carbon in subsoil horizons is located in spatially distinct parts of the soil profile. Soil Biol Biochem 41:256-261

Chamberlain PM, McNamara NP, Chaplow J, Stott AW, Black HIJ (2006) Translocation of surface litter carbon into soil by Collembola. Soil Biol Biochem 38:2655-2664

Dash M, Senapati B, Mishra C (1980) Nematode feeding by tropical earthworms. Oikos 34:322-325

Dempsey MA, Fisk MC, Yavitt JB, Fahey TJ, Balser TC (2013) Exotic earthworms alter soil microbial community composition and function. Soil Biol Biochem 67:263-270

Don A, Steinberg B, Schöning I, Pritsch K, Joschko M, Gleixner G, Schulze ED (2008) Organic carbon sequestration in earthworm burrows. Soil Biol Biochem 40:1803-1812

Doube BM, Schmidt O, Killham K, Correll R (1997) Influence of mineral soil on the palatability of organic matter for lumbricid earthworms: a simple food preference study. Soil Biol Biochem 29:569-575

Fahey TJ, Yavitt J, Sherman RE, Maerz JC, Groffman PM, Fisk MC, Bohlen PJ (2013) Earthworm effects on the incorporation of litter $\mathrm{C}$ and $\mathrm{N}$ into soil organic matter in a sugar maple forest. Ecol Appl 23:1185-1201

Gaillard V, Chenu C, Recous S (2003) Carbon mineralisation in soil adjacent to plant residues of contrasting biochemical quality. Soil Biol Biochem 35:93-99

Geisen S, Bandow C, Römbke J, Bonkowski M (2014a) Soil water availability strongly alters the community composition of soil protists. Pedobiologia 57:205-213

Geisen S, Weinert J, Kudryavtsev A, Glotova A, Bonkowski M, Smirnov A (2014b) Two new species of the genus Stenamoeba (Discosea, Longamoebia): cytoplasmic MTOC is present in one more amoebae lineage. Eur J Protistol 50:153-165

Görres JH, Amador JA (2010) Partitioning of habitable pore space in earthworm burrows. J Nematol 42:68-72

Görres JH, Savin MC, Amador JA (1997) Dynamics of carbon and nitrogen mineralization, microbial biomass, and nematode abundance within and outside the burrow walls of anecic earthworms (Lumbricus terrestris). Soil Sci 162:666-671

Griffith B, Türke M, Weisser WW, Eisenhauer N (2013) Herbivore behavior in the anecic earthworm species Lumbricus terrestris L.? Eur J Soil Biol 55:62-65

Hale CM, Frelich LE, Reich PB, Pastor J (2005) Effects of European earthworm invasion on soil characteristics in northern hardwood forests of Minnesota, USA. Ecosystems 8:911-927

Howe AT, Bass D, Vickerman K, Chao EE, Cavalier-Smith T (2009) Phylogeny, taxonomy, and astounding genetic diversity of Glissomonadida ord. nov., the dominant gliding zooflagellates in soil (Protozoa: Cercozoa). Protist 160:159-189

Jeuck A, Arndt H (2013) A short guide to common heterotrophic flagellates of freshwater habitats based on the morphology of living organisms. Protist 164:842

Kampichler C, Bruckner A, Kandeler E (2001) Use of enclosed model ecosystems in soil ecology: a bias towards laboratory research. Soil Biol Biochem 33:269-275

Lee JJ, Leedale GF, Bradbury P (2000) The illustrated guide to the Protozoa. Society of Protozoologists, USA, pp 1-689

Leibold MA (1995) The niche concept revisited: mechanistic models and community context. Ecology 76:1371-1382

Maraun M, Alphei J, Bonkowski M, Buryn R, Migge S, Peter M, Schaefer M, Scheu S (1999) Middens of the earthworm Lumbricus terrestris (Lumbricidae): microhabitats for micro-and mesofauna in forest soil. Pedobiologia 43:276-287

Nakagawa S, Schielzeth H (2012) A general and simple method for obtaining $\mathrm{R}^{2}$ from generalized linear mixed-effects models. Methods Ecol Evol 4:133-142 
Nuutinen V (2011) The meek shall inherit the burrow: feedback in earthworm soil modification. In: Karaca A (ed) Biology of earthworms. Springer, Berlin, pp 123-140

Oksanen J, Blanchet FG, Kindt R, Legendre P, Minchin PR, O'Hara RB, Simpson GL, Solymos P, Henry M, Stevens H, Wagner H (2012) Vegan: community ecology package., R Package Version 2.0-5. http://CRAN.R-project.org/package=vegan

Parkin TB, Berry EC (1999) Microbial nitrogen transformations in earthworm burrows. Soil Biol Biochem 31:1765-1771

Pinheiro J, Bates D, DebRoy S, Sarkar D (2013) R Development Core Team. nlme: linear and nonlinear mixed effects models., R package version 3.1-105. http://CRAN.R-project.org/package=nlme

R Development Core Team (2013) R: a language and environment for statistical computing. R Foundation for Statistical Computing, Vienna, Austria, http://www.R-project.org

Rumpel C, Dignac MF (2006) Gas chromatographic analysis of monosaccharides in a forest soil profile: analysis by gas chromatography after trifluoroacetic acid hydrolysis and reduction-acetylation. Soil Biol Biochem 38:1478-1481

Rumpel C, Eusterhues K, Kögel-Knabner I (2010) Non-cellulosic neutral sugar contribution to mineral associated organic matter in top- and subsoil horizons of two acid forest soils. Soil Biol Biochem 42:379 382

Sanaullah M, Chabbi A, Lemaire G, Charrier X, Rumpel C (2010) How does plant leaf senescence of grassland species influence decomposition kinetics and litter compounds dynamics? Nutr $\mathrm{Cycl}$ Agroecosyst 88:159-171

Sarakinos HC, Johnson ML, Zanden MJV (2002) A synthesis of tissuepreservation effects on carbon and nitrogen stable isotope signatures. Can J Zool 80:381-387

Schmidt O (1999) Intrapopulation variation in carbon and nitrogen stable isotope ratios in the earthworm Aporrectodea longa. Ecol Res 14: 317-328

Schmidt O, Scrimgeour CM (2001) A simple urea leaf-feeding method for the production of ${ }^{13} \mathrm{C}$ and ${ }^{15} \mathrm{~N}$ labelled plant material. Plant Soil 229:197-202

Smirnov AV, Brown S (2004) Guide to the methods of study and identification of soil gymnamoebae. Protistology 3:148-190
Smirnov AV, Chao E, Nassonova ES, Cavalier-Smith T (2011) A revised classification of naked lobose amoebae (Amoebozoa: Lobosa). Protist 162:545-570

Spielvogel S, Prietzel J, Kögel-Knabner I (2008) Soil organic matter stabilization in acidic forest soils is preferential and soil type-specific. Eur J Soil Sci 59:674-692

Stromberger ME, Keith AM, Schmidt O (2012) Distinct microbial and faunal communities and translocated carbon in Lumbricus terrestris drilospheres. Soil Biol Biochem 46:155-162

Szlavecz K (1985) The effect of microhabitats on the leaf litter decomposition and on the distribution of soil animals. Holarct Ecol 8:3338

Tao J, Chen X, Liu M, Hu F, Griffiths B, Li H (2009) Earthworms change the abundance and community structure of nematodes and protozoa in a maize residue amended rice-wheat rotation agro-ecosystem. Soil Biol Biochem 41:898-904

Thakuria D, Schmidt O, Finan D, Egan D, Doohan FM (2010) Gut wall bacteria of earthworms: a natural selection process. ISME J 4:357366

Tiunov AV, Scheu S (1999) Microbial respiration, biomass, biovolume and nutrient status in burrow walls of Lumbricus terrestris L. (Lumbricidae). Soil Biol Biochem 31:2039-2048

Tiunov AV, Bonkowski M, Bonkowski M, Tiunov JA, Scheu S (2001a) Microflora, Protozoa and Nematoda in Lumbricus terrestris burrow walls: a laboratory experiment. Pedobiologia 45:46-60

Tiunov AV, Dobrovol'skaya TG, Polyanskaya LM (2001b) Microbial complexes associated with inhabited and abandoned burrows of Lumbricus terrestris earthworm in soddy-podzolic soil. Eurasian Soil Sci 34:525-529

Uksa M, Schloter M, Kautz T, Athmann M, Köpke U, Fischer D (2015) Spatial variability of hydrolytic and oxidative potential enzyme activities in different subsoil compartments. Biol Fertil Soils 51:517-521

Yeates G, Bongers T, De Goede R, Freckman D, Georgieva S (1993) Feeding habits in soil nematode families and genera - an outline for soil ecologists. J Nematol 25:315

Zaller JG, Wechselberger KF, Gorfer M, Hann P, Frank T, Wanek W, Drapela T (2013) Subsurface earthworm casts can be important soil microsites specifically influencing the growth of grassland plants. Biol Fertil Soils 49:1097-1107 